\title{
Role of MIF/CD74 signaling pathway in the development of pleural mesothelioma
}

\author{
Cintia D'Amato-Brito1, Davide Cipriano1, Didier J. Colin², Stéphane Germain ${ }^{2}$, \\ Yann Seimbille ${ }^{3}$, John H. Robert ${ }^{1}$, Frédéric Triponez ${ }^{1}$, Véronique Serre-Beinier ${ }^{1}$ \\ ${ }^{1}$ Department of Thoracic and Endocrine Surgery, University Hospitals and University of Geneva, Geneva, Switzerland \\ ${ }^{2}$ MicroPET/SPECT/CT Imaging Laboratory, Centre for BioMedical Imaging (CIBM), University Hospitals and University \\ of Geneva, Geneva, Switzerland \\ ${ }^{3}$ Cyclotron Unit, University Hospitals and University of Geneva, Geneva, Switzerland \\ Correspondence to: Véronique Serre-Beinier, e-mail: Veronique.Serre-Beinier@hcuge.ch
}

Keywords: cancer, pleura, mesothelioma, macrophage migration inhibitory factor (MIF), CD74

Received: May 27, 2015

Accepted: January 26, 2016

Published: February 11, 2016

ABSTRACT

Macrophage migration inhibitory factor (MIF) is a pro-inflammatory cytokine implicated in acute and chronic inflammatory diseases. MIF is overexpressed in various tumors. It displays a number of functions that provide a direct link between the process of inflammation and tumor growth. Our group recently identified the MIF-receptor CD74 as an independent prognostic factor for overall survival in patients with malignant pleural mesothelioma.

In the present study, we compared the levels of expression of MIF and CD74 in different human mesothelioma cell lines and investigated their physiopathological functions in vitro and in vivo.

Human mesothelioma cells expressed more CD74 and secreted less MIF than non tumoral MeT5A cells, suggesting a higher sensitivity to MIF. In mesothelioma cells, high MIF levels were associated with a high multiplication rate of cells. In vitro, reduction of MIF or CD74 levels in both mesothelioma cell lines showed that the MIF/CD74 signaling pathway promoted tumor cell proliferation and protected MPM cells from apoptosis. Finally, mesothelioma cell lines expressing high CD74 levels had a low tumorigenic potential after xenogeneic implantation in athymic nude mice.

All these data highlight the complexity of the MIF/CD74 signaling pathway in the development of mesothelioma.

\section{INTRODUCTION}

Malignant pleural mesothelioma (MPM) is an aggressive cancer of the inner lining of the chest cavity which develops mainly after inhaling asbestos fibers. According to the WHO classification, malignant mesothelioma is either classified as epithelioid (mostly composed of epithelial-shaped cells), sarcomatoid (mostly composed of spindle-shaped cells), or biphasic (composed of both types of cells) [1]. In 2007, the WHO estimated that about 125 million people around the world were exposed to asbestos at work, and that at least 90,000 people died each year from asbestos-related diseases. In the next decades, MPM incidence will continue to increase, even in regions where the commercial use of asbestos has been banned (Europe, Australia and Japan) and will contribute to cancer mortality in countries lacking working protection and/or persisting with its use (Asia and India). While surgery is a valid option for patients with early stage MPM, most patients with locally advanced invasive disease are not amenable to surgical resection [2] and treatment is palliative chemotherapy combining cisplatin and pemetrexed. While this treatment may relieved symptoms, it provides only modest survivals, since median survival averages only 9-18 months from the time of diagnosis.

The exact mechanisms involved in the neoplastic transformation of mesothelial cells are still unknown. Identifying key genes related to the underlying oncogenic processes and understanding the malignant mesothelial cell 
regulation pathways are essential to develop more effective treatments. Initial tumor growth depends on increased cell proliferation and reduced cell death, both of which are stimulated by inflammation-driven mechanisms. Tumor cells trigger an intrinsic inflammatory response that builds up a protumorigenic microenvironment [3]. No study has precisely characterized the tumor inflammatory environment in the early development and growth of mesothelioma. Macrophage migration inhibitory factor (MIF) is a pro-inflammatory cytokine involved in both innate and adaptive immunity. Originally described as a $\mathrm{T}$ cell-derived product, MIF is released by numerous cell types and is involved in many inflammatory and autoimmune diseases [4]. Furthermore, MIF may be involved in cell proliferation and differentiation and several studies have reported increased MIF mRNA levels in tumor cells and pre-tumor states in prostate [5], colon [6-8], and hepatocellular cancers [9], adenocarcinomas of the lung [10], glioblastomas [11, 12] and melanomas [13]. Several groups have shown a correlation between MIF expression and cancer prognosis in hepatocellular carcinomas, colon and prostate cancers [8, 14, 15]. The invariant chain or CD74 was the first MIF surface receptor described [3]. Chemokine receptors CXCR2 and CXCR4 have also been shown to be MIF receptors [16-18]. In murine models of human colorectal adenoma [16] and metastatic breast cancer [19], inhibition of MIF expression by genetic deletion or RNA interference decreased tumor progression and metastasis. A reduction of tumor growth was also observed in sub-cutaneous human neuroblastoma [20] and prostate cancer xenografts [21], after inhibition of MIF expression by MIF antisens transfection or RNA interference or after treatment with anti-MIF antibodies or MIF inhibitors. Such a decrease of MIF activity was associated with inhibition of tumor angiogenesis [21].

Our group has recently shown that the majority of malignant mesothelial tumor cells express MIF and its receptor CD74, with a homogenous distribution between the different histological subtypes [22]. We also demonstrated that high levels of CD74 were an independent prognostic factor for prolonged overall survival in MPM patients. To clarify the potential involvement of MIF in MPM, we investigated the expression and the role of MIF and its receptors (CD74, CXCR2 and CXCR4) in viability, proliferation and in vivo tumorigenesis of human MPM cells.

\section{RESULTS}

In order to identify the role of MIF in MPM, mRNA and protein levels of MIF-receptors CD74 (Figure 1), CXCR2 and CXCR4 (Figure 2) and MIF (Figure 3), were assessed in six different human MPM cell lines of different histological types (JL-1, DM-3, H28, H2052, H2452 and MSTO) and in an non tumorigenic immortalised mesothelial cell line MeT5A (Table 1).

\section{MPM cell lines expressed higher levels of CD74 compared to mesothelial cell line MeT5A}

Expression of CD74 in MeT5A cells was weak to absent (Figure 1A and 1B). CD74 mRNA expression levels of all MPM cell lines studied were significantly higher than that of MeT5A cells (Figure 1A, $n=3 ; P<0.05$ ). CD74 total protein expression in MPM cell lines was higher than that of MeT5A cells except for JL-1 and MSTO cell lines (Figure 1B). Cell surface expression of CD74 was not detected using flow cytometry in all MPM cell lines studied and MeT5A cells (Supplementary Figure S1). Previous studies about cell surface CD74 showed that surface expression of newly synthesized CD74 complexes concern only few percents of cellular CD74 and is followed by a rapid internalization to the endosomal pathway [27] complicating cell surface detection of these complexes.

Thus, CD74 appeared to be primarily expressed in malignant mesothelial cells, indicating that such tumor cells may be prone to stimulation with MIF.

\section{MPM cell lines expressed similar levels of CXCR4 than mesothelial cell line MeT5A}

CXCR4 mRNA and protein levels (Figure 2A and 2B) were assessed by RT-qPCR and western blotting. No significant difference in CXCR4 expression levels between MPM cell lines compared to MeT5A was observed. A difference in cell surface expression of CXCR4 $(P<0.05)$ was detected between MeT5A and the MPM JL1 cells (Figure 3C) with a median fluorescence intensity of 2.9 $\pm 0.3(n=7)$ and $5.4 \pm 1.7(n=8)$ for MeT5A and JL1 respectively. In MPM cell lines, CXCR4 expression levels varied between the different cell lines studied and these levels of expression were not related to the histological type of the MPM.

The chemokine receptor $\mathrm{CXCR} 2$ has also been described as a receptor for MIF. CXCR2 mRNA levels were weak to absent in the MeT5A cells as well as MPM cells (data not shown) suggesting a very poor protein expression of CXCR2 in MPM and mesothelial cells.

\section{MPM cell lines secreted lower levels of MIF compared to mesothelial cell line MeT5A}

MIF mRNA and protein levels (Figure 3A and 3B) were assessed by RT-qPCR and western blotting. No significant difference in MIF expression levels between MPM cell lines compared to MeT5A was observed. In MPM cell lines, MIF expression levels varied between the different cell lines studied and these levels of expression were not related to the histological type of the MPM.

During tumorigenesis, tumor cells secrete growth factors and cytokines (including MIF) which amplify tumor cell transformation, activate their proliferation and 
modify the activation state of surrounding inflammatory cells. In order to determine whether MeT5A and MPM cells spontaneously secrete MIF in the culture medium, secreted MIF levels by MeT5A and MPM cell lines were measured after 48 h-culture by ELISA (Figure 3C). In all MPM cell lines studied, accumulated MIF concentrations in the supernatant reached levels significantly lower (from 2-fold to 14-fold lower for H28 and JL-1 respectively, $n=5 ; P<0.05)$ than the MIF secretion rate of MeT5A.

In summary, most MPM cell lines expressed higher levels of CD74 and secreted lower levels of MIF than mesothelial cell line MeT5A suggesting a higher sensitivity to MIF.

\section{MPM cells expressing high levels of MIF/CD74 and secreting high levels of MIF showed high multiplication rate}

We compared physiological characteristics, such as cell multiplication, cell proliferation and apoptosis of MeT5A cells with JL-1 and H28 MPM cell lines chosen in regard to their MIF/CD74 expressions and MIF secreting levels. As shown previously, JL-1 cells expressed the lowest MIF/CD74 levels and secreted the lowest MIF level and H28 cells expressed the highest MIF/CD74 levels and secreted the highest MIF level (Figures 1 and 3) of the six MPM cell lines studied.

The multiplication rate of the three cell lines was evaluated using a mitochondrial activity assay (MTT). Two days after plating $5 \times 10^{3}$ cells per well, cell number of MeT5A cells was not different than the number of JL-1 and H28 mesothelioma cells. H28 cell number was two-fold higher than the number of JL-1 cells (Figure 4A; $11,595 \pm 5,532$ cells, $n=9$, for MeT5A; 9, $058 \pm 4,336$ cells, $n=9$, for JL- 1 and $16,136 \pm 7,098$ cells, $n=15$, for $\mathrm{H} 28, P<0.05)$ indicating a higher multiplication rate for $\mathrm{H} 28$ cells. The population doubling time of MeT5A
$(18.9 \pm 4.5 \mathrm{~h}(n=4))$ was the lowest one compared to that of $\mathrm{H} 28(29.1 \pm 2.7 \mathrm{~h}(n=7 ; P<0.01))$ and JL-1 $(41.0 \pm 9.1 \mathrm{~h}$ $(n=6 ; P<0.01))$. The population doubling time of H28 cells was statistically lower than that of JL-1 cells $(P<0.05)$. It is well described that cancerous cell populations exhibit abnormally high cell proliferation and enhanced apoptotic cell death [23-25]. As the rate of tumor growth depends in part on an excess of proliferation over apoptosis, we determined and compared proliferation and apoptosis rates of JL-1, H28 and MeT5A cell lines. Statistically significant increasing proliferation rates (Figure 4B) were observed between JL-1 (20.7 $\pm 10.3 \%$ of EdU-positive cells, $n=62, P<0.0001)$, H28 (32.6 $\pm 13.0 \%$ of EdU-positive cells, $n=73)$ and MeT5A cells (39.3 \pm $11.6 \%$ of EdU-positive cells, $n=48$ ).

The level of apoptosis of $\mathrm{H} 28$ cells was lower than the level of apoptosis of MeT5A cells (Figure 4C and Table $2 ; 6.8 \pm 3.4 \%$ of total $\mathrm{H} 28$ cells $v s 21.9 \pm 3.0 \%$ of total MeT5A cells; $n=4 ; P<0.05)$. The level of apoptosis of JL- 1 cells tended to be lower than of MeT5A cells and slightly higher than that of $\mathrm{H} 28$ cells (Figure 4C; $12.5 \pm$ $5.9 \%$ of total JL- 1 cells, $n=4$ ). Necrosis, evaluated as the percentage of 7AAD-positive cells, was similar between JL-1, H28 and MeT5A cell lines $(5.0 \pm 5.3 \%, 1.4 \pm 0.5 \%$ and $2.1 \pm 2.6 \%$, respectively) (data not shown).

Finally, chemosensitivity of the three cell lines to cisplatin, a chemotherapeutic drug used in human MPM treatment was assessed. Cell multiplication was evaluated after $24 \mathrm{~h}$ of treatment with cisplatin using a MTT assay (Figure 4D). H28 and MeT5A cells were less sensitive to cisplatin treatment than JL-1 cells as after $24 \mathrm{~h}$ of cisplatin treatment, $67.9 \pm 33.4 \%(n=12)$ of $\mathrm{H} 28$ and $71.8 \pm 20.1 \%$ $(n=9)$ of MeT5A cells and only $38.1 \pm 13.5 \%(n=9)$ of JL-1 cells recovered compared to untreated cells.

All these data were analysed in regard to MIF-secreted level and CD74 expression in JL-1, H28 and MeT5A cell lines (Figures 1 and 3). Human MPM cell

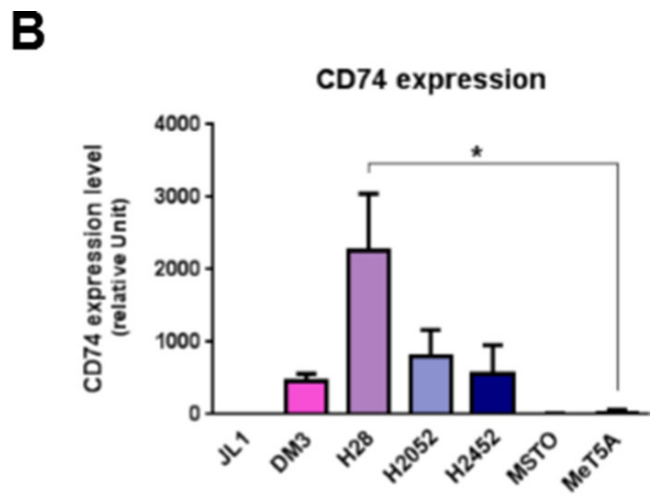

Figure 1: Mesothelioma cell lines overexpress CD74. MIF-receptors CD74 mRNA (A), and total protein (B) were measured in human immortalized normal mesothelial cell line (MeT5A) and different mesothelioma cell lines (JL-1, DM-3, H28, H2052, H2452, MSTO). Relative mRNA (A) or protein (B) expression levels were measured by qPCR and western blotting respectively. Data represent the mean values ( $\pm \mathrm{SD}$ ) of 3 to 6 independent experiments. significant difference Kruskal-Wallis test between normal mesothelial cell line MeT5A and mesothelioma cell lines: ${ }^{*} P<0.05$. 
Table 1: Mesothelioma cell lines studied

\begin{tabular}{|c|c|c|c|c|c|c|}
\hline Cell line & JL-1 & DM-3 & $\mathrm{H} 28$ & H2052 & H2452 & MSTO \\
\hline Histological type of original tumor & Epithelioid & Sarcomatoid & Not done & Not done & Biphasic & Biphasic \\
\hline Reference & [42] & [42] & & & [45] & [45] \\
\hline
\end{tabular}

line H28 (expressing high level of CD74 and secreting high level of MIF) showed a high level of multiplication and proliferation rate associated with a low level of apoptosis rate. In contrast, the MPM cell line JL-1 (expressing low level of CD74 and secreting low level of MIF) showed a low level of multiplication and proliferation rate associated with a high level of apoptosis rate. These data suggested that MIF increased cell viability through increase of proliferation and decrease of apoptosis of MPM cells. Additionally, high level of secreted MIF and CD74 expression was also associated to a lower sensitivity to cisplatin.

\section{MIF or CD74 deficiency impacts $\mathrm{H} 28$ and $\mathrm{H} 2052$ cell proliferation and apoptosis}

In order to assess whether MIF binding to CD74 explained differences in multiplication (proliferation and apoptosis) of MPM cells, we investigated cell multiplication, proliferation and apoptosis of $\mathrm{H} 28$ and $\mathrm{H} 2052$ cells after small interfering RNA (siRNA) down-regulation of MIF or CD74. H28 and H2052 cells transfected with a non-coding (NC) siRNA were used as control cells. siRNA down-regulation of MIF led to a reduction of MIF protein expression of $75 \%$ and $68 \%$ for H28 and H2052 cells respectively (Figure 5A, left panel; MIF expression in MIF siRNA treated cells was $25 \pm 14 \%$ and $32 \pm 18 \%$ of MIF expression in NC siRNA treated cells in $\mathrm{H} 28$ and $\mathrm{H} 2052$ cells respectively, $n=7$ to $8 ; P<0.001$ and $P<0.01$ ) and a reduction of MIF secretion of $41 \%$ and $63 \%$ in $\mathrm{H} 28$ and $\mathrm{H} 2052$ respectively (Figure 5A, right panel; MIF secretion by MIF siRNA treated cells was $59 \pm 13 \%$ and $37 \pm 7 \%$ of MIF secretion by NC siRNA treated cells for $\mathrm{H} 28$ and $\mathrm{H} 2052$ respectively; $n=5$ to 7 , $P<0.05)$. The same results were obtained by transfecting MPM cells with two different siRNA specific for MIF (Hs_MIF_5 or Hs_MIF_6) individually or by pooling them. Multiplication rate of MIF siRNA treated-cells was
A

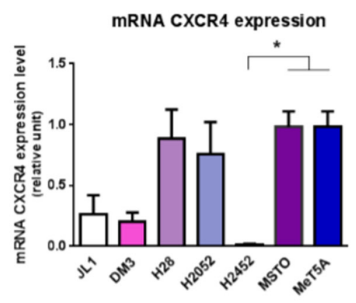

B

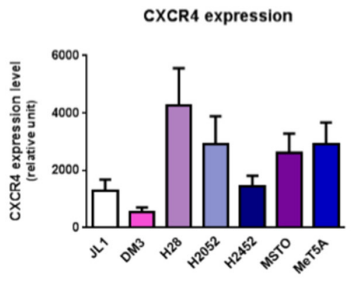

C

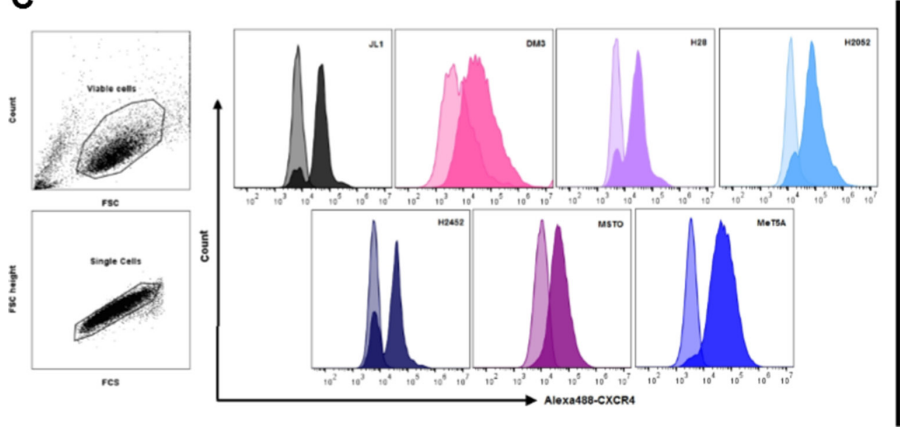

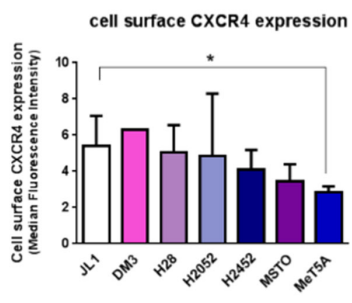

Figure 2: Mesothelioma cell lines express CXCR4. MIF-receptors CXCR4 mRNA (A), total protein (B) and cell surface protein (C) were measured in human immortalized normal mesothelial cell line (MeT5A) and different mesothelioma cell lines (JL-1, DM-3, H28, H2052, H2452, MSTO). Relative mRNA (A) or protein (B) expression levels were measured by qPCR and western blotting respectively. Data represent the mean values $( \pm \mathrm{SD})$ of 3 to 6 independent experiments. CXCR4 distribution on the cell surface was analysed by flow cytometry (C). Cells were treated with EDTA and stained with anti-CXCR4 antibody followed by Alexa488-conjugated anti-IgG. Controls received equivalent concentrations of isotype-matched IgG. Viable mesothelial and mesothelioma cells were first gated according to SSC-A vs FSC-A scatted plot and doublet were excluded using a pulse geometry gate FSC-H x FSC-A plot (C, left panel). For all histograms, data are shown as cell number vs. the relative fluorescence. The light-coloured histogram depicts isotype control, whereas the dark-coloured one represents CXCR4 antibody. Each histogram shows data from a single representative experiment although each analysis was repeated at least seven times. CXCR4 expression was normalized according to the median fluorescence intensity with the isotype-matched IgG (C, right panels). Kruskal-Wallis test between normal mesothelial cell line MeT5A and mesothelioma cell lines: $* P<0.05$. 
reduced of $39 \%$ and $40 \%$ for $\mathrm{H} 28$ and $\mathrm{H} 2052$ respectively, compared to that of NC siRNA treated cells (Figure 5C, $61 \pm 17 \%$ and $60 \pm 34 \%$ for $\mathrm{H} 28$ and $\mathrm{H} 2052$ respectively, $n=6-7, P<0.01)$. This reduction in cell multiplication was explained by a reduction of $13 \%$ of cell proliferation of MIF siRNA-treated H28 cells (Figure 5D, $87 \pm 24 \%$, $n=5$ for $\mathrm{H} 28$ cells; $120 \pm 34 \%, n=6$ for H2052 cells) and an increase of $213 \%$ and $334 \%$ of cell apoptosis for H28 and H2052 (Figure 5E, $213 \pm 86 \%$ and $334 \pm 278 \%$ for $\mathrm{H} 28$ and $\mathrm{H} 2052, n=7-13, P<0.05)$.

CD74 expression of H28 and H2052 cells treated with CD74 siRNA was reduced by $96 \%$ and $98 \%$, respectively (Figure 5B; $4 \pm 6 \%, n=4$ for $\mathrm{H} 28$, and $2 \pm 4 \%$, $n=6$ for $\mathrm{H} 2052 ; P<0.05)$. The same results were obtained transfecting $\mathrm{H} 28$ and $\mathrm{H} 2052$ cells with two different siRNA specific for CD74 (Hs_CD74_2 or Hs_CD74_5) individually or by pooling them. Multiplication rate of H28 and H2052 transfected with CD74 siRNA was reduced of $29 \%$ and $49 \%$ respectively, compared to that of NC siRNA treated cells (Figure 5C, 71\% $\pm 20 \%, n=6$, $P<0.05$ for $\mathrm{H} 28 ; 51 \pm 26 \%, n=7 ; P<0.01$ for $\mathrm{H} 2052)$. CD74 siRNA-treated H28 and H2052 cells showed a decrease in cell proliferation compared to NC siRNA treated cells (Figure 5D; $37 \pm 29 \%, n=5, P<0.05$ for $\mathrm{H} 28$; and $59 \pm 33 \%, n=6$ for H2052) and an increase in cell apoptosis (Figure 5E; $245 \pm 143 \%, n=4$ for $\mathrm{H} 28$ and 427 $\pm 389 \%, n=7$ for $\mathrm{H} 2052 ; P<0.05)$.

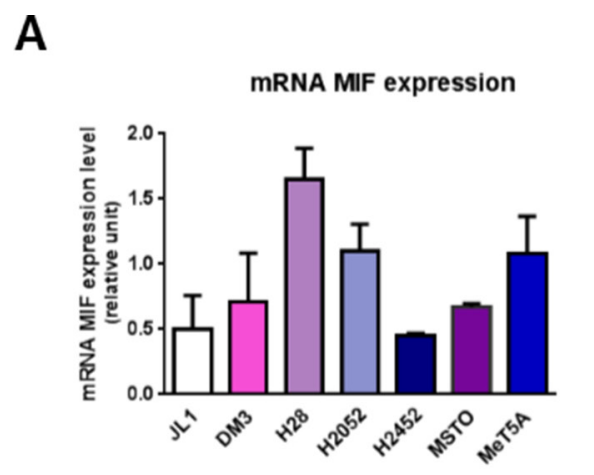

In summary, in human MPM H28 and H2052 cell lines, a MIF expression and secretion reduction led to a decrease in cell multiplication due to an increase of cell apoptosis. Additionally, a reduction in CD74 expression led to a decrease of cell multiplication, due to a decrease of cell proliferation and an increase of cell apoptosis.

\section{MPM cells expressing higher level of CD74 showed lower tumorigenic potential}

In order to analyse the association between MIF/ CD74 stimulated pathway and the tumorigenic potential of MPM cells, we followed xenografts development of two human MPM cell lines expressing high levels of CD74 (H28 and H2052, see Figure 1B), and two human MPM cell lines expressing low levels of CD74 (JL-1 and MSTO, see Figure 1B). Cell lines were injected individually subcutaneously (s.c.) and intra-pleuraly (i.pl.) into athymic nude mice (immunodeficiency affecting $\mathrm{T}$ cells), and tumor development were assessed using caliper (for s.c. tumors) and positron emission tomography/computed tomography (PET/CT) scans (for pleural tumors).

MSTO, JL-1 and H2052 cell lines formed s.c. tumors (Figure 6A) in nearly all injected mice (10/10; $7 / 7$ and 5/6, respectively). MSTO and JL-1 cell lines generated fast-growing s.c. tumors in $100 \%$ injected mice (Figure 6A). MSTO injected mice were euthanized 33

B

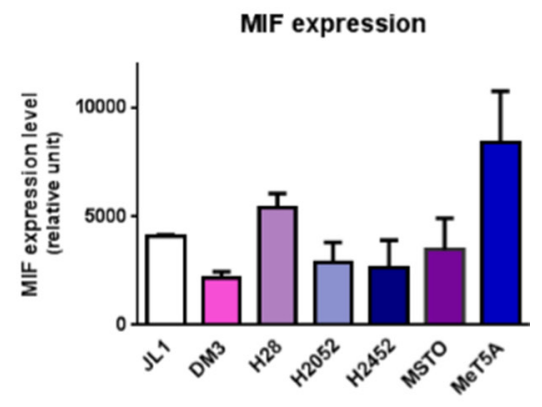

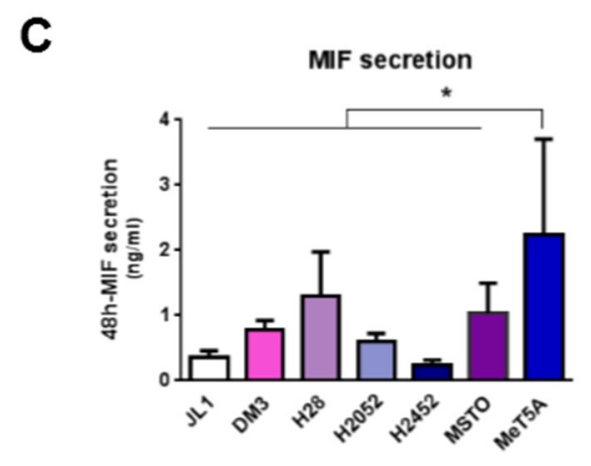

Figure 3: Mesothelioma cell lines express MIF. MIF mRNA (A) total protein (B) and secretion levels (C) were measured in human immortalized normal mesothelial cell line (MeT5A) and different mesothelioma cell lines (JL-1, DM-3, H28, H2052, H2452, MSTO). Relative mRNA (A) or total protein (B) expression levels were measured by qPCR and western blotting respectively. MIF concentrations in $48 \mathrm{~h}$-cultured media were measured by ELISA (C). Data represent the mean values ( \pm SD) of 3 to 6 independent experiments. KruskalWallis test between normal mesothelial cell line MeT5A and mesothelioma cell lines: ${ }^{*} P<0.05$. 
days-post injection at the first clinical signs of distress. Sub-cutaneously JL-1 tumors were explanted 46 dayspost injection. At these time points, the mean volume for s.c. tumors was $1,097 \pm 286 \mathrm{~mm}^{3}(n=6)$ for MSTO and $1,863 \pm 1,042 \mathrm{~mm}^{3}(n=5)$ for JL- 1 tumors. Growth of s.c. H2052 xenograft was slower than that of MSTO and JL-1 xenografts. The first identified H2052 tumors were measured at day 48-post injection ( $\left.49 \pm 56 \mathrm{~mm}^{3}, n=6\right)$. At day 102-post injection, H2052 injected mice showed clinical signs of distress and were euthanized. The mean volume for s.c. H2052 tumors at the end of the experiment was $244 \pm 205 \mathrm{~mm}^{3}(n=4)$. No mice injected s.c. with H28 cells developed tumors until 155 days after cell injection.

MSTO, JL-1 and H2052 pleural tumors were identified in the thoracic cavity using 2-deoxy-2-[ $\left.{ }^{18} \mathrm{~F}\right]$ fluoro-D-glucose ( $\left[{ }^{18} \mathrm{~F}\right] \mathrm{FDG}$ )-PET/CT analyses (Figure $6 \mathrm{~B}$, top panels) in nearly all injected mice $(9 / 10,5 / 10$ and $5 / 6$, respectively). Post-mortem examination showed that athymic nude mice injected with MSTO, JL-1 and H2052 cells had extensive pleural tumors. Most of tumors were free in the thoracic cavity; some tumors were attached to the thoracic muscles and the diaphragm and few to the lung. No mice injected i.pl. with H28 cells developed tumors until 155 days after injection. In order to estimate the MIF and CD74 expression in intra-pleural MPM tumors developed into athymic nude mice, we performed immunohistochemical staining for MIF, CD74 and the coreceptor of CD74, CD44 on intra-pleural JL-1, H2052 and MSTO tumors. As shown in Figure 7, cytoplasmic MIF was detected in tumor cells of JL-1, H2052 and MSTO tumors. As expected neither CD74 nor its co-receptor CD44 were detected in JL-1 tumor cells. Cytoplasmic and membranous expression of CD74 was detected in H2052 tumor cells. These cells also expressed high amount of cytoplasmic and membranous CD44. Cytoplasmic and
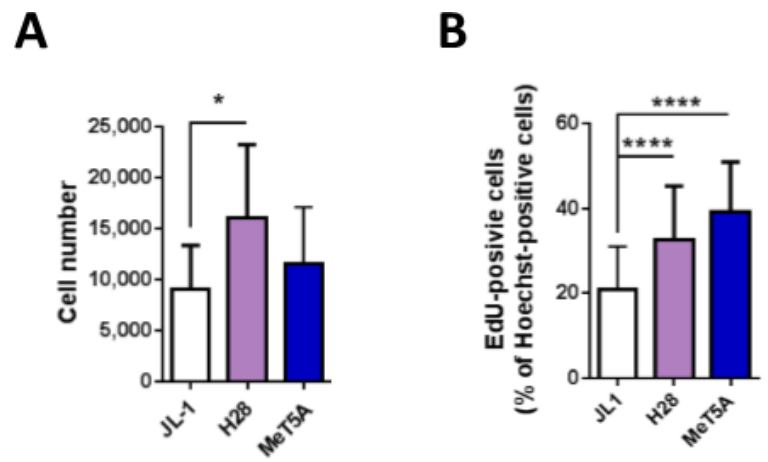

membranous CD74 was also detected in MSTO tumor cells as well as CD44. CD44 labeling of MSTO tumors was less intense than that of $\mathrm{H} 2052$.

Our in vivo data suggested that CD74/CD44 expression was negatively associated with in vivo tumorigenesis in MPM.

\section{DISCUSSION}

MIF is a pro-inflammatory cytokine overexpressed in various cancers $[5-10,12,13]$. It may play an important role in carcinogenesis by promoting cell proliferation, tumor angiogenesis and metastasis [26]. Up to now, no study has addressed the role of MIF in MPM. Recently, we have shown that the majority of the malignant mesothelial tumor cells expressed MIF and its receptor CD74, with a homogenous distribution between the different histotypes. We also demonstrated that high expression of CD74 was an independent prognostic factor for prolonged overall survival in MPM patients [22].

In this study, we characterized the expression and impact of MIF on human MPM cell lines. MIF protein expression was confirmed in immortalized mesothelial MeT5A cell line and in several MPM cell lines derived from epithelioid, sarcomatoid and biphasic human MPM. MIF protein expression level was not significantly different between MeT5A and MPM cells, suggesting that de novo synthesis and intracellular protein storage did not differ between normal and malignant mesothelial cells. In contrast, MIF secretion was lower in MPM cells compared to MeT5A cells. These lower levels of secreted MIF could be related to the higher level of expression of MIF-receptor CD74 in MPM cells, conferring a higher sensitivity to MIF of MPM cells compared to normal mesothelial cells. The very low level of CD74 in normal mesothelial cell line MeT5A suggest that these cells are
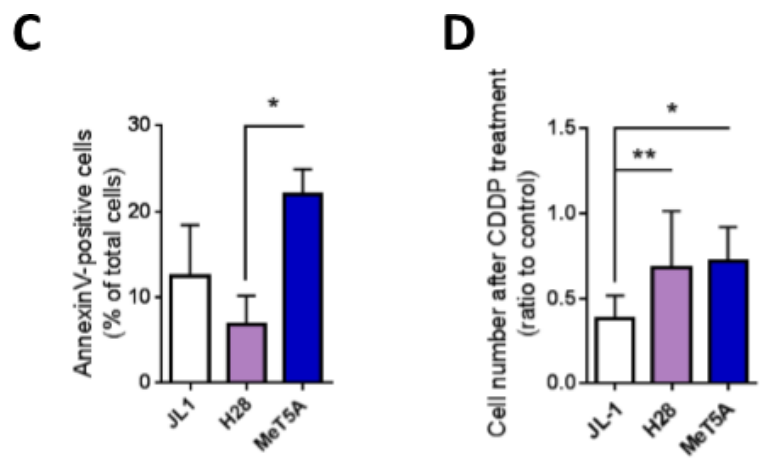

Figure 4: High levels of MIF and CD74 in mesothelioma cells are associated with high multiplication rate. JL-1, H28 and MeT5A cells were cultured for $24 \mathrm{~h}$. Cell multiplication (A) was measured using a MTT assay. Cell proliferation (B) was estimated by EdU incorporation after $2 \mathrm{~h}$ cultured with EdU. Proliferation rate was calculated as the percentage of EdU ${ }^{+}-H_{0 e c h s t}{ }^{+}$double-positive cells (Zeiss Apotome, 20× magnification, Axiovision 4.6). Cell apoptosis (C) was analyzed using Annexin-V-PE/7-AAD double staining. Effect of cisplatin on cell multiplication (D) was assessed using the MTT assay performed on mesothelioma cells cultured for $24 \mathrm{~h}$ with $100 \mathrm{mmol} / \mathrm{L}$ of cisplatin. Control was cells cultured for $24 \mathrm{~h}$ without cisplatin. Bars are mean values $( \pm \mathrm{SD})$ for $n=4-15$ independent experiments. Kruskal-Wallis test between normal mesothelial cell line MeT5A and mesothelioma cell lines: ${ }^{*} P<0.05, * * P<0.01$, $* * * P<0.001$ and $* * * * P<0.0001$. 
Table 2: Cell apoptosis of MeT5A, JL-1 and H28 cell lines expressed in \% of total cells

\begin{tabular}{|c|c|c|c|c|c|c|c|c|c|c|c|}
\hline & \multicolumn{3}{|c|}{ MeT5A } & \multicolumn{4}{|c|}{ JL-1 } & \multicolumn{4}{|c|}{$\mathbf{H 2 8}$} \\
\hline & Mean & SD & $n$ & Mean & SD & $n$ & $\begin{array}{c}p v s \\
\text { MeT5A }\end{array}$ & Mean & SD & $n$ & $\begin{array}{c}p v s \\
\text { MeT5A }\end{array}$ \\
\hline Cell apoptosis (AnnexinV-positive cells) & 21.9 & 3.0 & 4 & 12.5 & 5.9 & 4 & ns & 6.8 & 3.4 & 4 & $<0.05$ \\
\hline $\begin{array}{l}\text { Early apoptosis (AnnexinV-pos and } \\
\text { 7AAD-negative cells) }\end{array}$ & 14.2 & 2.5 & 4 & 7.6 & 4.1 & 4 & ns & 4.3 & 2.5 & 4 & $<0.05$ \\
\hline $\begin{array}{l}\text { Late apoptosis death (AnnexinV-pos and } \\
\text { 7AAD-positive cells) }\end{array}$ & 7.8 & 2.3 & 4 & 5.0 & 2.1 & 4 & ns & 2.5 & 1.0 & 4 & $<0.05$ \\
\hline
\end{tabular}

not sensitive to MIF, explaining in part why their high MIF secretion level was not correlated to their multiplication rate. Cell surface CD74 could not be detected on MPM cells using flow cytometry. Previous studies about cell surface CD74 showed that surface expression of newly synthesized CD74 complexes concern only few percents of cellular CD74 and is followed by a rapid internalization to the endosomal pathway [27] complicating cell surface detection of these complexes. Expression of the chemokine receptors CXCR2 and CXCR4, described as MIF receptors, was characterized as the same levels in mesothelial and MPM cell lines suggesting that these receptors are not implicated in MPM cell multiplication.

In the MPM cell lines studied, we observed that the higher CD74 expression and MIF secreted levels, the higher the multiplication rate was, suggesting that MIF signaling through CD74 could play a role in MPM cell proliferation and apoptosis. This role was confirmed by reducing MIF and CD74 expression in MPM H28 and H2052 cells using specific siRNA. A reduction in CD74 expression led to a decrease in the multiplication rate due to a decrease of the proliferation and an increase of the apoptosis rates. Reducing MIF expression and secretion had the same effect on multiplication suggesting that MIF signal transduction is initiated by binding to CD74. MIF reduction did not change the proliferation rate. This could potentially be explained either by a resting MIF level sufficient to activate proliferation of MPM cells or by pro-stimulatory effect of another CD74 ligand such as the functional homolog of MIF, the D-dopachrome tautomerase [28].

Our data suggest that secreted MIF (or MIF homolog) from tumor cells has pro-stimulatory and anti-apoptotic effects on MPM cells. This pro-stimulatory effect could also be due, in situ, to MIF secreted by cells from the tumor microenvironment, such as tumor-associated
A

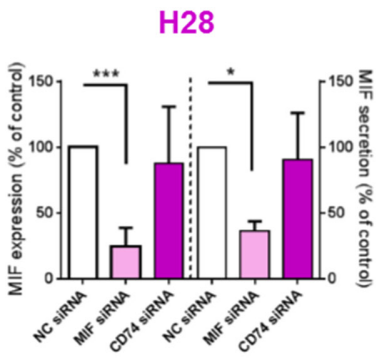

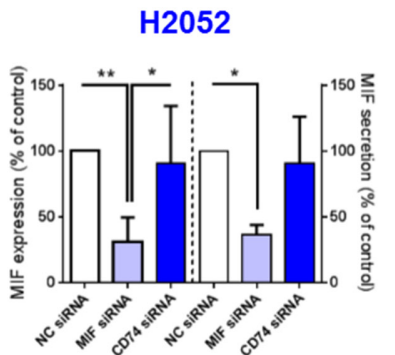

D

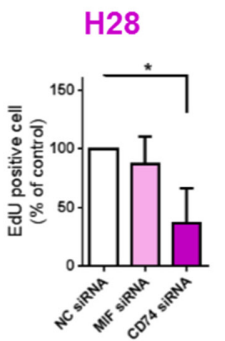

B

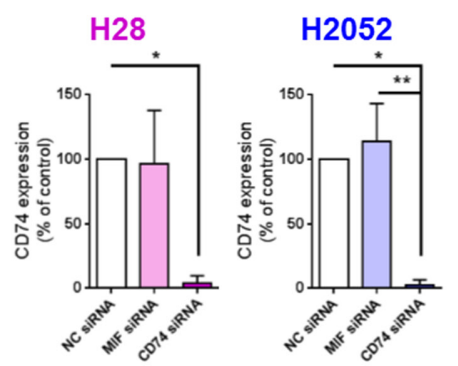

C

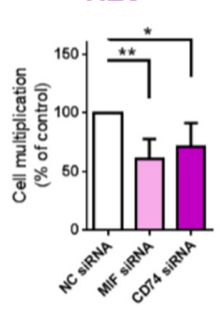

H2052

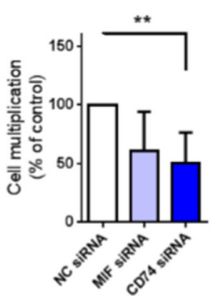

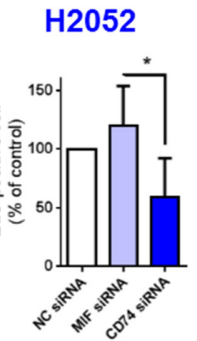

E

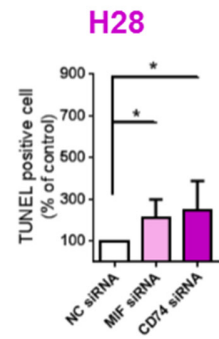

H2052

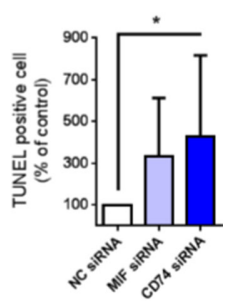

Figure 5: MIF and CD74 promote $\mathrm{H} 28$ and $\mathrm{H} 2052$ cell multiplication in vitro, increasing cell proliferation and decreasing cell apoptosis. H28 (pink bars) and H2052 (blue bars) cells transfected with NC-siRNA, MIF-siRNA and CD74-siRNA were assessed after $48 \mathrm{~h}$ of culture, for MIF expression (A left panel), MIF secretion (A right panel) and CD74 expression (B) by western blot and ELISA. The multiplication of transfected H28 and H2052 cells (C) was evaluated by total cell counting (Hoechst-positive nuclei) after $48 \mathrm{~h}$ of culture. Proliferation (D) and apoptosis (E) rates of transfected H28 and H2052 cells were evaluated by EdU incorporation and TUNEL assay, respectively. Data represent the mean values $( \pm \mathrm{SD})$ for $n=4-8$ independent experiments. Kruskal-Wallis test between cells transfected with NC, MIF or CD74 siRNAs: $* P<0.05, * * P<0.01$, and $* * * P<0.001$. 
macrophages, tumor-infiltrating lymphocytes, or cancerassociated fibroblasts [29-33]. In several tumoral cells (breast, colon, prostate, lung, ...), MIF signaling in cancer is well described to be triggered by its receptor CD74 [21, 34, 35]. Previously, in tumoral cells of human MPM explants, we showed [22] a co-expression of MIF and CD74 suggesting that MIF effect on MPM cells was triggered in part by binding to CD74. In summary, in MPM cell lines, activated MIF/CD74 pathway has a protumorigenic function by increasing tumor cell proliferation and protecting them from apoptosis.

In vivo data obtained from the development of MPM into athymic nude mice showed at contrary that the lower
CD74 expression level is, the higher the tumorigenic potential is. These results should be related to our previous results obtained on human tissue array [22] showing that low CD74 expression level in MPM cells was associated with a low patient survival rate. We also observed an up-regulation of CD74 expression in situ in MSTO-211H tumors. These data therefore showed additional regulatory pathway on CD74 expression in vivo. These different results highlight the complex role of MIF and its receptor CD74 in tumor growth. The effect of MIF and CD74 on carcinogenesis seems to change with the cell type as well as the stage of the cancer. This may be a consequence of the activation of different signaling pathways. Several

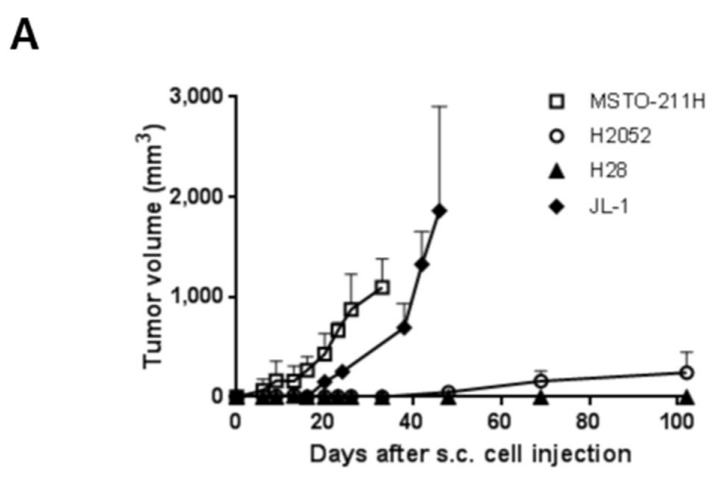

B

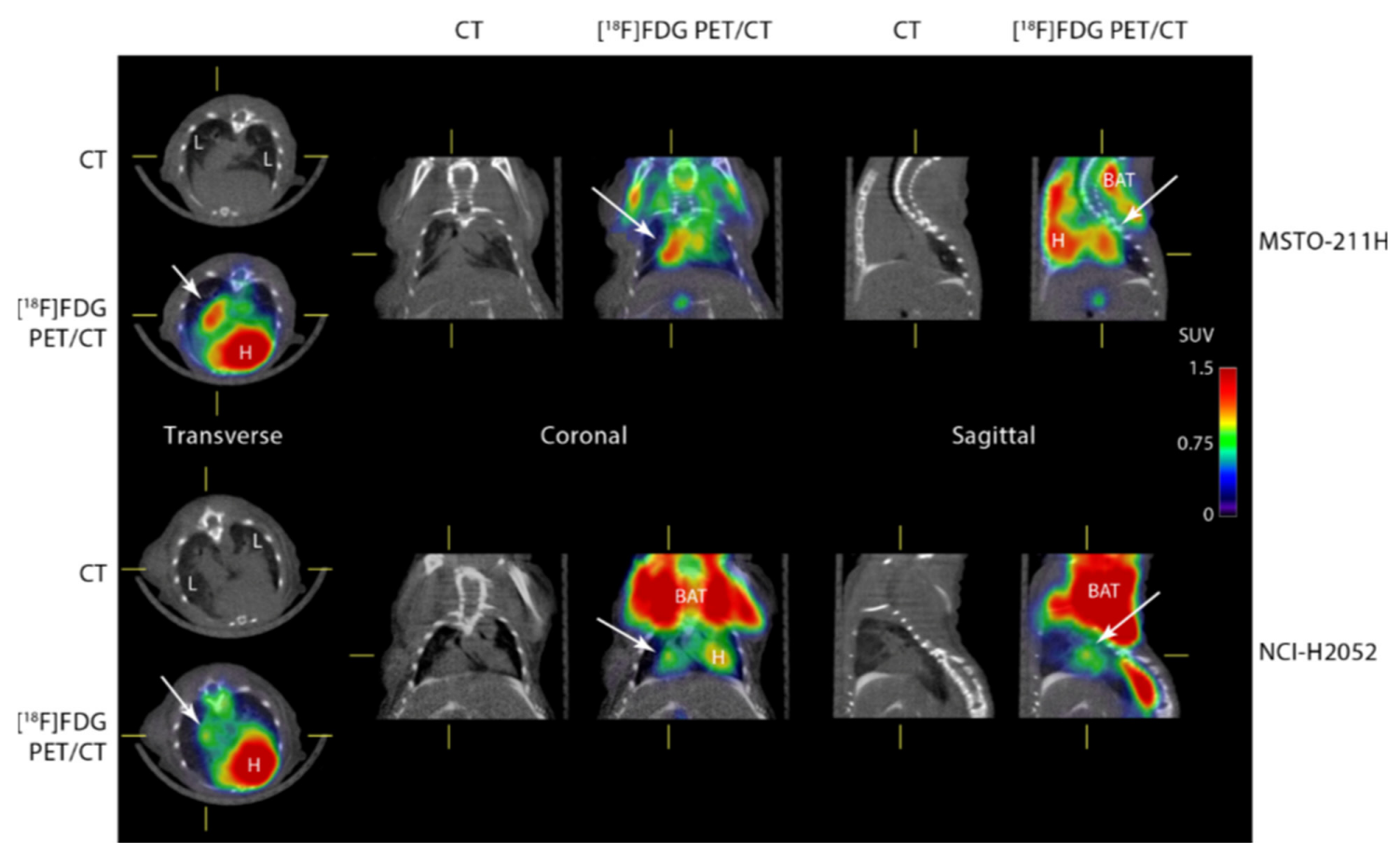

Figure 6: The tumorigenic potential of mesothelioma is negatively associated to CD74 levels. Human mesothelioma cells (MSTO, JL-1, H2052 and H28) were injected s.c. $\left(1 \times 10^{6}\right.$ cells $)$ and i.pl. $\left(1 \times 10^{6}\right.$ cells $)$ into athymic nude mice $(n=4-6$ per group). Sub-cutaneous tumor growth rates were assessed using caliper measurements (A). Intra-pleural tumors were followed using $\left[{ }^{18} \mathrm{~F}\right]$ FDG-PET/CT. Representative PET/CT of MSTO (at 23 days post i.pl. injection) and H2052 tumors (at 69 days post i.pl. injections) in nude mice are shown (B). The images shown were trans-axial slices containing the FDG-avid tumors and organs, with CT (gray scale) providing anatomic references and PET (pseudo-color scale) showing the location and intensity of high tumor and organ glucose utilization. CT: CT mediastinal window; $\left[{ }^{18} \mathrm{~F}\right] \mathrm{FDG}$ PET/CT: PET-CT fused image; White arrows indicated mesothelioma tumors. $\mathrm{L}=$ lung, $\mathrm{H}=\mathrm{heart}$, $\mathrm{BAT}=$ brown adipose tissue. 
studies reported the activation of the extracellular signal regulated kinase (ERK) 1 and 2 in the mitogen-activated protein kinase pathway, and the PI3K/Akt/SRC signal transduction cascade $[3,36,37]$ subsequently to the binding of MIF to its receptor complex CD74/CD44. These activated pathways upregulate cell proliferation, decrease cell apoptosis and enhance cell migration $[21,38]$. In contrast, other studies showed that MIF can activate the AMPK pathway, leading in some cancers to a decrease in cell proliferation, cell viability and in their metastatic potential [39, 40]. Finally, we observed differences in tumor development after s.c. or i.pl. injection with H2052 cells. H2052 tumors developed slowly but extensively in the thoracic cavity while s.c tumors poorly grew. These differences could be due to differences in the vascularization, growth factors and immune cells in the environment of these both sites. While s.c graft site has the advantage to be easily accessible, it is not representative of the environment in which the tumor originated. Wang Y

H\&E
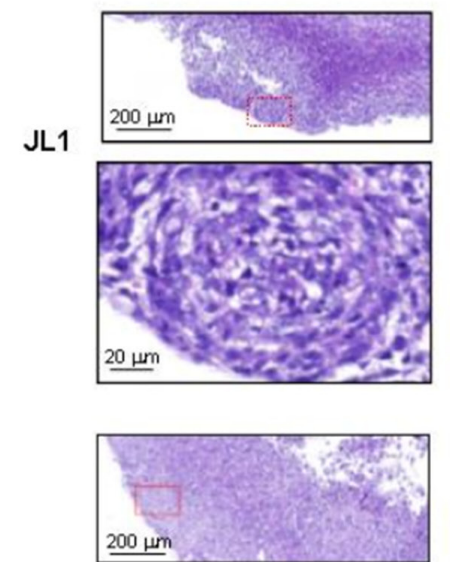

MSTO
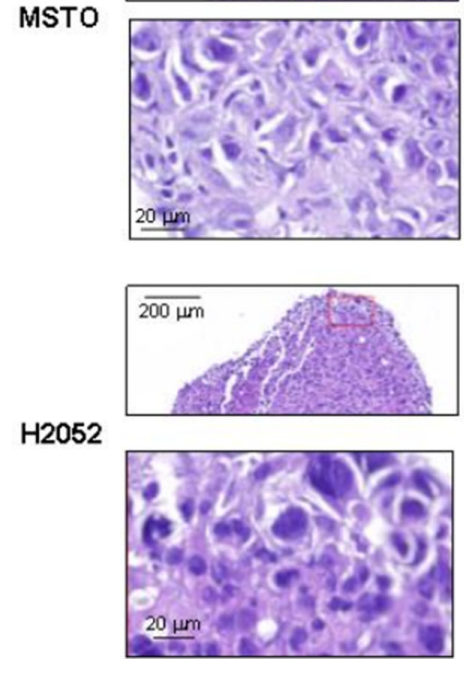

$\mathrm{H} 2052$

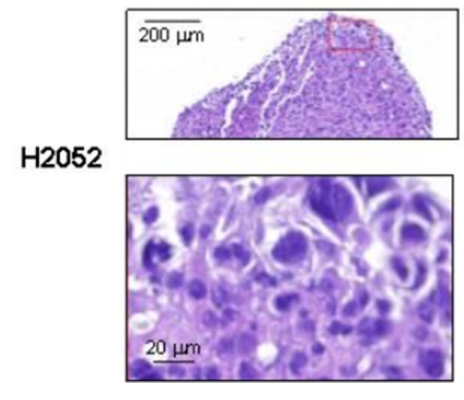

MIF
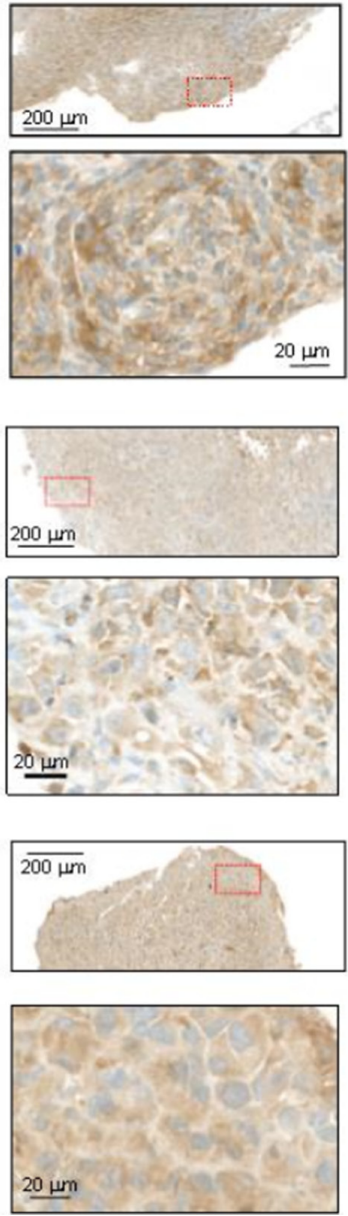

et al. [41] showed that the histology of human prostate tumors implanted into immunodefficient mice was best in the orthotopically grafted samples and that s.c. grafted tissues had the poorest profile of histopathologic differentiation. The orthotopic graft site provides a tumor microenvironment that closely reflects the clinical situation. The use of orthotopic sites versus other sites may well be important in the metastatic spread patterns of any advance malignant graft. The use of the orthotopic thoracic site for xenografting has not been widespread, due largely to the technical difficulties in reaching, and monitoring tumor development in this location. In our study, the progression of mesothelioma in the pleural cavity was easily monitored by using PET/CT imaging, offering a new valuable tool for evaluation of anticancer therapy for MPM. In the future, in order to clarify the complex role of MIF and/or CD74 from tumor and stromal cells in MPM development, we plan to perform i.pl. syngeneic implantations of murine mesothelioma cells
CD74
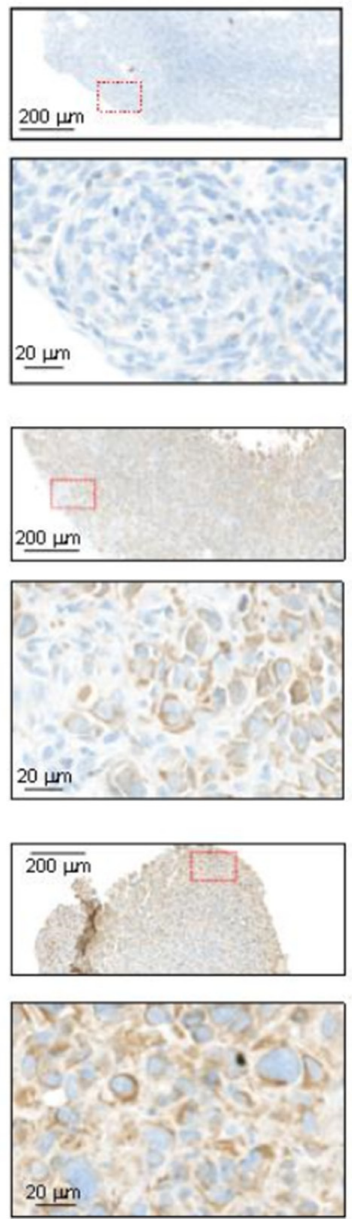

CD44
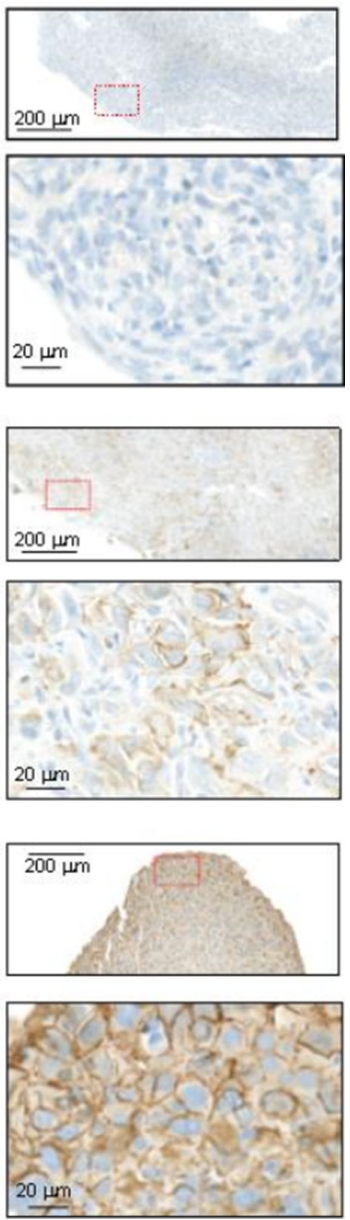

Figure 7: MIF, CD74 and CD44 expressions in intra-pleural human mesothelioma. Human mesothelioma cells (JL-1, MSTO, and H2052) were injected i.pl. (1.10 cells) into athymic nude mice ( $n=4-6$ per group). Representative photomicrographs of JL-1 (A), MSTO (B) and H2052 (C) intra-thoracic tumors stained with H \& E, anti-MIF, anti-CD74 and anti-CD44 antibody. Representative photomicrographs are shown (red box magnified in the bottom panel). Scale bars: $200 \mu \mathrm{m}$ and $20 \mu \mathrm{m}$. 
deleted or not in MIF or CD74 expression into wild-type or MIF-deficient or CD74-deficient mice and study tumor development, tumor angiogenesis and identify the inflammatory cells recruited by the host.

In conclusion, the results of the present study showed that most human MPM cell lines expressed higher level of CD74 and secreted lower level of MIF than MeT5A mesothelial cell line. Decreasing MIF or CD74 expression in H28 and H2052 MPM cells reduced multiplication rate of the tumor cells due to a reduction in proliferation and an increase in apoptosis. Finally, in vivo data following xenogeneic human MPM cells implanted into athymic mice suggested that CD74 expression was negatively associated with in vivo tumorigenesis in MPM. All these data showed the complex role of MIF/CD74 pathway on MPM development with, on one hand, a promoting effect on tumor cell viability and on the other hand, a promoting effect on mesothelioma cell-stroma interactions.

\section{MATERIALS AND METHODS}

\section{Cell culture}

The non-tumorigenic immortalized mesothelial cell line MeT5A and the MPM cell lines H28 (NCI-H-28), H2052 (NCI-H2052), MSTO (MSTO211H) and H2452 (NCI-H2452) were purchased from American Type Culture Collection. The MPM cell lines JL-1 and DM-3 were established and characterized in our laboratory from human biopsies [42]. Cells were routinely cultured in RPMI 1640 medium containing $10 \%$ (v/v) fetal calf serum (complete RPMI, Life Technologies). Cultures were grown at $37^{\circ} \mathrm{C}$ in $5 \% \mathrm{CO}_{2}$.

\section{RNA interference}

H28 and H2052 cells were transfected twice. A reverse transfection was first performed followed by a forward transfection $48 \mathrm{~h}$ latter, according to the manufacturer's instructions with $67 \mathrm{nmol} / 1$ of commercially available MIF (Hs_MIF_5 FlexiTube siRNA ref. SI02781065; Hs_MIF_6 FlexiTube siRNA ref. SI02781247), CD74 (Hs_CD74_2 FlexiTube siRNA ref. SI00063049; Hs CD74 5 FlexiTube siRNA ref. SI03058405), or nonspecific scramble siRNA oligonucleotides (AllStars Negative Control siRNA ref. 1027281) from Qiagen using INTERFERin $\left({ }^{\circledR}\right)$ transfection reagent (Polyplus). Downregulation of MIF and CD74 expressions was measured $48 \mathrm{~h}$ after transfection by RT-qPCR and immunoblot analysis. MIF secretion, cell viability and proliferation and cell apoptosis were measured $48 \mathrm{~h}$ after transfection.

\section{Total RNA isolation and real-time RT-PCR}

The expression of MIF, CD74, CXCR2, CXCR4, GAPDH, GUSB, EEFLA1 and TBP mRNAs was evaluated by quantitative RT-PCR analysis. Total mRNAs from each cell lines was extracted by Qiagen RNEasy Midi extraction Kit (Qiagen) according to manufacturer's instructions.

Reverse transcription was performed from $0.5 \mu \mathrm{g}$ of total RNA using PrimerScript reverse transcriptase enzyme (Takara bio inc. Kit) and a mix of random hexamers - oligo $\mathrm{d}(\mathrm{T})$ primers, following suppliers instructions.

Real-time RT-PCR was performed on each sample in triplicate performed from $500 \mathrm{ng}$ cDNA using an ABI 7900HT SDS system with Power SYBR Green PCR Master Mix (Applied Biosystems, Foster City, California). SYBR green primers were designed using the program Primer Express v 2.0 (Applied Biosystems) with default parameters and obtained from Invitrogen. Primer sequences for the targeted human genes are available upon request. Results were normalized to the expression levels of GAPDH, GUSB, EEFLA1 and TBP expression genes, used as housekeeping genes. Normalisation factor and fold changes were calculated using the GeNorm method [43].

\section{Cell lysis and western blotting analysis}

Cell lysates for western blotting were prepared in sample buffer $1 \times(62.5 \mathrm{mmol} / \mathrm{l}$ Tris- $\mathrm{HCl} \mathrm{pH} 7.4,2 \%$ $(\mathrm{w} / \mathrm{v})$ SDS, $10 \% \quad(\mathrm{v} / \mathrm{v})$ glycerol, and $1 \% \quad(\mathrm{v} / \mathrm{v})$ $\beta$-mercaptoethanol) supplemented with protease inhibitor cocktail (Roche Molecular Diagnostics), and $10 \mathrm{mmol} / \mathrm{l}$ phosphatase inhibitors sodium orthovanadate (Sigma) and sodium pyrophosphate (Sigma). Protein concentrations of all samples were determined with the amido black method [44] or using a colorimetric assay (BCA Protein Assay Kit, Pierce). Total protein extracts (5 to $25 \mu$ g were loaded on a SDS-PAGE gel. Electrophoresed samples were electroblotted onto polyvinylidene fluoride (PVDF) membranes (Immobilon-P, Millipore) in the presence of $0.01 \%(\mathrm{w} / \mathrm{v})$ SDS and $20 \%(\mathrm{v} / \mathrm{v})$ methanol. The membranes were saturated for $1 \mathrm{~h}$ at room temperature (RT) in a 10 $\mathrm{mmol} / \mathrm{l}$ Tris-HCl buffer (pH 7.4) containing $150 \mathrm{mmol} / 1$ $\mathrm{NaCl}, 0.1 \%(\mathrm{v} / \mathrm{v})$ Tween-20, and 5\% (w/v) milk (TBS/T/ milk), and then incubated overnight at $4{ }^{\circ} \mathrm{C}$ with rabbit polyclonal primary antibodies diluted in TBS/T/milk at 1/1000 for GAPDH (\#2118, Cell Signaling Technology), 1/200 for CXCR4 (ab2074, Abcam), 1/1000 for CD74 (HPA010592, Sigma) and 1/1000 for MIF (BR47, from the Roger lab, Lausanne, Switzerland). Detection was performed using an anti-rabbit HRP-conjugated secondary antibody (Bio-Rad Laboratories) and an enhanced chemiluminescence detection system (ECL Plus western blotting detection reagents from Amersham, GE Healthcare). Quantifications were then performed using 
a ChemiDoc XRS and Quantity One software (Bio-Rad Laboratories).

\section{Flow cytometry}

Cell populations were analyzed with a BD Accuri C6 instrument (Becton-Dickinson). Data were analyzed with FlowJo (Tree Star). Adherent cells were detached using EDTA $0.5 \mathrm{mM}$, washed and resuspended in staining buffer (PBS, FBS 3\%, EDTA 5 mM). Cells were stained with PE-conjugated anti-CD74 antibody (LN2, Biolegend) for $30 \mathrm{~min}$ at $4^{\circ} \mathrm{C}$. CXCR4 was stained with rabbit anti-human CXCR4 antibody (ab2074, Abcam) for $30 \mathrm{~min}$ at $4{ }^{\circ} \mathrm{C}$ followed by Alexa488-conjugated anti-rabbit IgG (A11008, Invitrogen) for $30 \mathrm{~min}$. at $4^{\circ} \mathrm{C}$. Controls received equivalent concentrations of isotype-matched $\mathrm{IgG}$.

\section{Immunohistochemistry analysis}

$4 \mu \mathrm{m}$ thick mesothelioma tumor sections from formalin fixed paraffin embedded samples were analysed by immunohistochemistry using anti-MIF (gift of Thierry Roger, Lausanne), anti-CD74 (HPA010592, Sigma) and anti-CD44 antibodies (HPA005785, Sigma) using the Ventana Discovery automated staining system (Ventana Medical Systems, Tucson, AZ, USA). Ventana reagents for the entire procedure were used. Antigenicity was retrieved by heating slides in $\mathrm{CC} 1$ cell conditioning solution for 20 min (EDTA antigen retrieval solution $\mathrm{pH} 8.4 ; 20 \mathrm{~min}$ for CD74 and CD44, $36 \mathrm{~min}$ for MIF). After automatic deparaffinization and heating, slides were incubated 30 $\min$ at $37^{\circ} \mathrm{C}$ with primary antibodies diluted at $1 / 300$ (MIF), 1/1000 (CD74) and 1/500 (CD44) in antibody diluent from Dako (S2022). Detection of anti-MIF, anti-CD74 and anti-CD44 antibodies were performed using the rabbit OmniMap kit (760-149).

\section{Biochemical analyses}

Thirty thousand cells were seeded onto 24-well microplates in $500 \mu \mathrm{l} /$ well of complete RPMI medium. Supernatants were removed $48 \mathrm{~h}$ after culture, centrifuged $20 \mathrm{~min}$ at $1,000 \mathrm{~g}$ and stored at $-20^{\circ} \mathrm{C}$. MIF levels in medium supernatant were detected using the Human MIF Duoset kit (R \& D System).

\section{Cell viability}

Cell viability was determined by the reduction of 3-(4, 5-dimethylthiazol-2-yl)-2, 5-diphenyltetrazolium bromide (MTT, Sigma-Aldrich). Five thousand cells were seeded onto 96-well microplates in complete RPMI. After overnight incubation, cells were serum-starved for $24 \mathrm{~h}$ in RPMI medium supplemented with $1 \%(\mathrm{w} / \mathrm{v})$ human serum albumin (HSA). Then, medium was replaced and cells were cultured in complete RPMI with or without $100 \mathrm{mmol} / 1$ of cisplatin Ebewe ${ }^{\circledR}$ (Sandoz Pharmaceuticals SA) for 48 $\mathrm{h}$ at $37^{\circ} \mathrm{C}$. MTT solution $(500 \mu \mathrm{g} / \mathrm{ml}$ in RPMI $/ 1 \% \mathrm{HSA})$ was added for $2 \mathrm{~h}$ at $37^{\circ} \mathrm{C}$. Absorbance was read in a spectrophotometer at $570 \mathrm{~nm}$.

\section{Cell proliferation}

Cell proliferation was measured by performing 5-ethynyl-20-deoxyuridine (EdU) incorporation assay, using the Click-iT EdU imaging kit (Life Technologies) according to the manufacturer's instructions. Cells were cultured in 8-chamber slides (Lab-Tek permanox chamber slide from Nunc) at a density of $25 \times 10^{3}$ cells $/ \mathrm{cm}^{2}$. After overnight incubation, and serum-starvation for $24 \mathrm{~h}$ in RPMI medium supplemented with $1 \%(\mathrm{w} / \mathrm{v}) \mathrm{HSA}$, medium was replaced by complete RPMI, and cells were incubated for another $24 \mathrm{~h}$ at $37^{\circ} \mathrm{C}$. Then, $5 \mu \mathrm{M}$ of EdU was added to each chamber and cells were cultured for additional $2 \mathrm{~h}$ at $37^{\circ} \mathrm{C}$. The cells were fixed with $10 \%(\mathrm{v} / \mathrm{v})$ formalin for $20 \mathrm{~min}(\mathrm{RT})$ and permeabilized with $0.5 \%(\mathrm{v} / \mathrm{v})$ Triton X-100 for $10 \mathrm{~min}(\mathrm{RT})$. After washing with PBS, cells were incubated with the EdU reagent cocktail for $30 \mathrm{~min}$ at RT. Then, the cells were stained with mounting medium ProTaqs Mount Fluor (BIOCYC) containing Hoechst33342. The EdU (green) and Hoechst (blue) positive nuclei were counted and the EdU incorporation rate was expressed as the ratio of EdU positive cells to total Hoechst positive cells.

\section{Cell apoptosis analysis}

Cell apoptosis was evaluated using Annexin-Vphycoerythrin/7-amino-actinomycin D (Annexin-V$\mathrm{PE} / 7-\mathrm{AAD})$ double staining. Cells $\left(2 \times 10^{5}\right.$ to $\left.4 \times 10^{5}\right)$ were cultured for $24 \mathrm{~h}$ in non-adherent $35 \mathrm{~mm}$-dishes, in complete RPMI. After washes with cold PBS and Annexin $\mathrm{V}$ Binding Buffer (100 mmol/1 Hepes, $1.4 \mathrm{~mol} / \mathrm{l} \mathrm{NaCl}$, $25 \mathrm{mmol} / \mathrm{C} \mathrm{CaCl}_{2}$ ), cells were resuspended in $100 \mu \mathrm{l}$ of Annexin V Binding Buffer and incubated with $2.5 \mu \mathrm{l}$ of PE Annexin V (BioLegend \#640912) and $7 \mu 1$ of 7-AAD (BD Pharmingen \# 51-2359KC) for $15 \mathrm{~min}$ at RT in the dark. Annexin V Binding Buffer $(100 \mu \mathrm{l})$ were added to each tube and annexin and 7-AAD fluorescences were analysed with an Accuri C6 flow cytometer (BD). For each measurement, $5 \times 10^{4}$ cells were counted. Dot plots and histograms were analysed by BD Accuri ${ }^{\mathrm{TM}} \mathrm{C} 6$ software (BD). Annexin V-positive cells were considered in the early stage of apoptosis; Annexin V- and 7-AADpositive cells were considered in the late stage of apoptosis or necrotic. Annexin V- and 7-AAD-negative cells correspond to the viable cell fraction.

H28 cell apoptosis after transfection with siRNA was evaluated using a terminal deoxynucleotidyl transferase dUTP nick-end labeling (TUNEL) assay. Forty-eight 
hours after transfection, H28 cells were fixed in $10 \%(\mathrm{v} / \mathrm{v})$ formalin and TUNEL assay (In Situ Cell Death Detection Kit, TMR red, Roche Diagnostics) was performed according to the manufacturer's instructions. Briefly, cells were permeabilized in $0.1 \%(\mathrm{v} / \mathrm{v})$ triton-X100 in PBS for $10 \mathrm{~min}$ and incubated with the reaction mixture containing the enzyme terminal deoxynucleotidyl transferase and the fluorescent TMR-conjugated dUTP for $1 \mathrm{~h}$ at $37^{\circ} \mathrm{C}$. Labeled DNA was visualized by fluorescence microscopy.

\section{Sub-cutaneous and i.pl. implantations of MPM cells in nude mice}

Mice were anaesthetized with isoflurane and MPM cells (MSTO, JL-1, H2052 and H28) were injected s.c. $\left(1 \times 10^{6}\right.$ tumor cells suspended in $200 \mu$ l of of a matrix containing $30 \%$ of RPMI and $70 \%$ of HyStem-C hydrogel (ESI BIO, Alameda, CA, USA)) on the right dorsa and into the left pleural cavity $\left(1 \times 10^{6}\right.$ tumor cells suspended in $50 \mu \mathrm{l}$ of RPMI) of 8-week-old athymic female nude mice nu/nu (Harlan) ( $n=5$ or 6 per group). Once a week, volumes of s.c. tumors were measured using calipers and calculated using the following formula: $(\mathrm{mm})) / 2$

(Long axis $(\mathrm{mm}) \mathrm{x}$ short axis $(\mathrm{mm}) \mathrm{x}$ short axis

Intra pleural tumors were followed by 2-deoxy2- $\left[{ }^{18} \mathrm{~F}\right]$ fluoro-D-glucose ([ $\left.\left.{ }^{18} \mathrm{~F}\right] \mathrm{FDG}\right)-\quad$ PET/computed tomography (CT) scans. PET/CT was performed using a Triumph PET/SPECT/CT system (Trifoil, Chatsworth, CA, USA). The mice were fasted for $12 \mathrm{~h}$ and blood glucose was measured before each scan. Mice were anesthetized with $2 \%$ isoflurane and were i.v. injected retro-orbitally with 5-6 MBq of $\left[{ }^{18} \mathrm{~F}\right] \mathrm{FDG}$. Mice were then left awake at RT during an uptake time of $60 \mathrm{~min} .10 \mathrm{~min}$ prior to PET scan, mice were injected intraperitoneally with $700 \mu \mathrm{L}$ of $132 \mathrm{mg} / \mathrm{ml}$ meglumine ioxitalamate (Telebrix, 6\% m/v iodide, Guerbet AG, Zürich, Switzerland) to delineate the abdominal region and subjected to $\mathrm{CT}$ scans. Images were obtained at $80 \mathrm{kVp}, 160 \mu \mathrm{A}$, and 1024 projections were acquired during the $360^{\circ}$ rotation with a field of view of $71.3 \mathrm{~mm}(1.7 \times$ magnification $)$. After $60 \mathrm{~min}$ of $\left[{ }^{18} \mathrm{~F}\right] \mathrm{FDG}$ uptake, PET scans were started for a duration of $20 \mathrm{~min}$. PET scans were reconstructed with the built-in LabPET software using an OSEM3D (20 iterations) algorithm and images were calibrated in $\mathrm{Bq} / \mathrm{ml}$ by scanning a phantom cylinder. The Triumph XO software, which uses a back-projection engine, was used to reconstruct the CT scans with a matrix of 512 and a voxel size of $0.135 \mathrm{~mm}$. CT scans were co-registered with the PET scans using the plugin Vivid (Trifoil) for Amira (FEI, Hillsboro, OR, USA) and exported as dicom files. The software Osirix (Pixmeo, Bernex, Switzerland) was used to quantitatively analyse the datasets and generate pictures.

At the end of the experiment, all mice were euthanized and closely examined for the presence of thoracic tumors. This study was conducted under protocols revised and approved by the institutional animal care and use committee and by Geneva's veterinarian state office.

\section{Statistics}

Results were presented as means \pm SD. Statistical differences among three or more groups were examined by a Kruskal-Wallis test. Differences between pairs of groups were examined for statistical significance using the unpaired Mann-Whitney $U$ test. A $P$ value $<0.05$ was considered as statistically significant.

\section{ACKNOWLEDGMENTS}

We thank Logeina Borayi and Romain Baechler for their excellent technical assistance.

\section{FUNDING}

This study was supported by grants from the Boninchi Foundation and the Geneva Cancer League (to V.S-B) and from the Centre for BioMedical Imaging (CIBM) (to DJC, SG and YS).

\section{CONFLICTS OF INTEREST}

C.B., D.C., D.J.C., S.G., Y.S., JH.R, F.T. and V.S-B. have nothing to declare.

\section{REFERENCES}

1. Travis WD BE, Muller-Hermelink HK, Harris CC. (2004). Pathology and genetics of tumours of the lung, pleura, thymus and heart: IARC Press. Lyon).

2. Opitz I. Management of malignant pleural mesotheliomaThe European experience. Journal of thoracic disease. 2014; 6:S238-252.

3. Leng L, Metz CN, Fang Y, Xu J, Donnelly S, Baugh J, Delohery T, Chen Y, Mitchell RA, Bucala R. MIF signal transduction initiated by binding to CD74. J Exp Med. 2003; 197:1467-1476.

4. Calandra T, Roger T. Macrophage migration inhibitory factor: a regulator of innate immunity. Nat Rev Immunol. 2003; 3:791-800.

5. Meyer-Siegler K, Fattor RA, Hudson PB. Expression of macrophage migration inhibitory factor in the human prostate. Diagn Mol Pathol. 1998; 7:44-50.

6. Liehn EA, Kanzler I, Konschalla S, Kroh A, Simsekyilmaz S, Sonmez TT, Bucala R, Bernhagen J, Weber C. Compartmentalized protective and detrimental effects of endogenous macrophage migration-inhibitory factor mediated by CXCR2 in a mouse model of myocardial ischemia/reperfusion. Arteriosclerosis, thrombosis, and vascular biology. 2013; 33:2180-2186. 
7. Goh SH, Hong SH, Lee BC, Ju MH, Jeong JS, Cho YR, Kim IH, Lee YS. eIF3m expression influences the regulation of tumorigenesis-related genes in human colon cancer. Oncogene. 2011; 30:398-409.

8. Legendre H, Decaestecker C, Nagy N, Hendlisz A, Schuring MP, Salmon I, Gabius HJ, Pector JC, Kiss R. Prognostic values of galectin-3 and the macrophage migration inhibitory factor (MIF) in human colorectal cancers. Mod Pathol. 2003; 16:491-504.

9. Ren Y, Tsui HT, Poon RT, Ng IO, Li Z, Chen Y, Jiang G, Lau C, Yu WC, Bacher M, Fan ST. Macrophage migration inhibitory factor: roles in regulating tumor cell migration and expression of angiogenic factors in hepatocellular carcinoma. Int J Cancer. 2003; 107:22-29.

10. Kamimura A, Kamachi M, Nishihira J, Ogura S, Isobe H, Dosaka-Akita H, Ogata A, Shindoh M, Ohbuchi T, Kawakami Y. Intracellular distribution of macrophage migration inhibitory factor predicts the prognosis of patients with adenocarcinoma of the lung. Cancer. 2000; 89:334-341.

11. Bach JP, Deuster O, Balzer-Geldsetzer M, Meyer B, Dodel R, Bacher M. The role of macrophage inhibitory factor in tumorigenesis and central nervous system tumors. Cancer. 2009; 115:2031-2040.

12. Bacher M, Schrader J, Thompson N, Kuschela K, Gemsa D, Waeber G, Schlegel J. Up-regulation of macrophage migration inhibitory factor gene and protein expression in glial tumor cells during hypoxic and hypoglycemic stress indicates a critical role for angiogenesis in glioblastoma multiforme. Am J Pathol. 2003; 162:11-17.

13. Shimizu T, Abe R, Nakamura H, Ohkawara A, Suzuki M, Nishihira J. High expression of macrophage migration inhibitory factor in human melanoma cells and its role in tumor cell growth and angiogenesis. Biochem Biophys Res Commun. 1999; 264:751-758.

14. Hira E, Ono T, Dhar DK, El-Assal ON, Hishikawa Y, Yamanoi A, Nagasue N. Overexpression of macrophage migration inhibitory factor induces angiogenesis and deteriorates prognosis after radical resection for hepatocellular carcinoma. Cancer. 2005; 103:588-598.

15. Meyer-Siegler KL, Bellino MA, Tannenbaum M. Macrophage migration inhibitory factor evaluation compared with prostate specific antigen as a biomarker in patients with prostate carcinoma. Cancer. 2002; 94:1449-1456.

16. Wilson JM, Coletta PL, Cuthbert RJ, Scott N, MacLennan K, Hawcroft G, Leng L, Lubetsky JB, Jin KK, Lolis E, Medina F, Brieva JA, Poulsom R, et al. Macrophage migration inhibitory factor promotes intestinal tumorigenesis. Gastroenterology. 2005; 129:1485-1503.

17. Bernhagen J, Krohn R, Lue H, Gregory JL, Zernecke A, Koenen RR, Dewor M, Georgiev I, Schober A, Leng L, Kooistra T, Fingerle-Rowson G, Ghezzi P, et al. MIF is a noncognate ligand of CXC chemokine receptors in inflammatory and atherogenic cell recruitment. Nat Med. 2007; 13:587-596.
18. Tarnowski M, Grymula K, Liu R, Tarnowska J, Drukala J, Ratajczak J, Mitchell RA, Ratajczak MZ, Kucia M. Macrophage migration inhibitory factor is secreted by rhabdomyosarcoma cells, modulates tumor metastasis by binding to CXCR4 and CXCR7 receptors and inhibits recruitment of cancer-associated fibroblasts. Mol Cancer Res. 2010; 8:1328-1343.

19. Simpson KD, Templeton DJ, Cross JV. Macrophage migration inhibitory factor promotes tumor growth and metastasis by inducing myeloid-derived suppressor cells in the tumor microenvironment. J Immunol. 2012; 189:5533-5540.

20. Ren Y, Chan HM, Fan J, Xie Y, Chen YX, Li W, Jiang GP, Liu Q, Meinhardt A, Tam PK. Inhibition of tumor growth and metastasis in vitro and in vivo by targeting macrophage migration inhibitory factor in human neuroblastoma. Oncogene. 2006; 25:3501-3508.

21. Meyer-Siegler KL, Iczkowski KA, Leng L, Bucala R, Vera PL. Inhibition of macrophage migration inhibitory factor or its receptor (CD74) attenuates growth and invasion of DU-145 prostate cancer cells. J Immunol. 2006; 177:8730-8739.

22. Otterstrom C, Soltermann A, Opitz I, Felley-Bosco E, Weder W, Stahel RA, Triponez F, Robert JH, SerreBeinier V. CD74: a new prognostic factor for patients with malignant pleural mesothelioma. Br J Cancer. 2014.

23. Wei N, Serino G, Deng XW. The COP9 signalosome: more than a protease. Trends in biochemical sciences. 2008; 33:592-600.

24. Bech-Otschir D, Kraft R, Huang X, Henklein P, Kapelari B, Pollmann C, Dubiel W. COP9 signalosome-specific phosphorylation targets $\mathrm{p} 53$ to degradation by the ubiquitin system. The EMBO journal. 2001; 20:1630-1639.

25. Hartwell LH, Kastan MB. Cell cycle control and cancer. Science. 1994; 266:1821-1828.

26. Damico R, Simms T, Kim BS, Tekeste Z, Amankwan H, Damarla M, Hassoun PM. p53 mediates cigarette smokeinduced apoptosis of pulmonary endothelial cells: inhibitory effects of macrophage migration inhibitor factor. Am J Respir Cell Mol Biol. 2011; 44:323-332.

27. Starlets D, Gore Y, Binsky I, Haran M, Harpaz N, Shvidel L, Becker-Herman S, Berrebi A, Shachar I. Cell-surface CD74 initiates a signaling cascade leading to cell proliferation and survival. Blood. 2006; 107:4807-4816.

28. Merk M, Zierow S, Leng L, Das R, Du X, Schulte W, Fan J, Lue H, Chen Y, Xiong H, Chagnon F, Bernhagen J, Lolis E, et al. The D-dopachrome tautomerase (DDT) gene product is a cytokine and functional homolog of macrophage migration inhibitory factor (MIF). Proc Natl Acad Sci U S A. 2011; 108:E577-585.

29. Zhang M, Yan L, Kim JA. Modulating mammary tumor growth, metastasis and immunosuppression by siRNAinduced MIF reduction in tumor microenvironment. Cancer Gene Ther. 2015.

30. Wang X, Chen T, Leng L, Fan J, Cao K, Duan Z, Zhang X, Shao C, Wu M, Tadmori I, Li T, Liang L, Sun D, et al. 
MIF Produced by Bone Marrow-Derived Macrophages Contributes to Teratoma Progression after Embryonic Stem Cell Transplantation. Cancer Res. 2012; 72:2867-2878.

31. Zhang L, Ye SB, Ma G, Tang XF, Chen SP, He J, Liu WL, Xie D, Zeng YX, Li J. The expressions of MIF and CXCR4 protein in tumor microenvironment are adverse prognostic factors in patients with esophageal squamous cell carcinoma. J Transl Med. 2013; 11:60.

32. Li J, Mo HY, Xiong G, Zhang L, He J, Huang ZF, Liu ZW, Chen QY, Du ZM, Zheng LM, Qian CN, Zeng YX. Tumor microenvironment macrophage inhibitory factor directs the accumulation of interleukin-17-producing tumorinfiltrating lymphocytes and predicts favorable survival in nasopharyngeal carcinoma patients. J Biol Chem. 2012; 287:35484-35495.

33. Mitchell RA, Yaddanapudi K. Stromal-dependent tumor promotion by MIF family members. Cell Signal. 2014; 26:2969-2978.

34. Coleman AM, Rendon BE, Zhao M, Qian MW, Bucala R, Xin D, Mitchell RA. Cooperative regulation of non-small cell lung carcinoma angiogenic potential by macrophage migration inhibitory factor and its homolog, D-dopachrome tautomerase. J Immunol. 2008; 181:2330-2337.

35. Verjans E, Noetzel E, Bektas N, Schutz AK, Lue H, Lennartz B, Hartmann A, Dahl E, Bernhagen J. Dual role of macrophage migration inhibitory factor (MIF) in human breast cancer. BMC Cancer. 2009; 9:230.

36. Lue H, Thiele M, Franz J, Dahl E, Speckgens S, Leng L, Fingerle-Rowson G, Bucala R, Luscher B, Bernhagen J. Macrophage migration inhibitory factor (MIF) promotes cell survival by activation of the Akt pathway and role for CSN5/JAB1 in the control of autocrine MIF activity. Oncogene. 2007; 26:5046-5059.

37. Shi X, Leng L, Wang T, Wang W, Du X, Li J, McDonald C, Chen Z, Murphy JW, Lolis E, Noble P, Knudson W, Bucala R. CD44 is the signaling component of the macrophage migration inhibitory factor-CD74 receptor complex. Immunity. 2006; 25:595-606.
38. Lee CY, Su MJ, Huang CY, Chen MY, Hsu HC, Lin CY, Tang $\mathrm{CH}$. Macrophage migration inhibitory factor increases cell motility and up-regulates alphavbeta3 integrin in human chondrosarcoma cells. J Cell Biochem. 2012; 113:1590-1598.

39. Kim HS, Kim MJ, Kim EJ, Yang Y, Lee MS, Lim JS. Berberine-induced AMPK activation inhibits the metastatic potential of melanoma cells via reduction of ERK activity and COX-2 protein expression. Biochem Pharmacol. 2012; 83:385-394.

40. Lee CW, Wong LL, Tse EY, Liu HF, Leong VY, Lee JM, Hardie DG, Ng IO, Ching YP. AMPK promotes p53 acetylation via phosphorylation and inactivation of SIRT1 in liver cancer cells. Cancer Res. 2012; 72:4394-4404.

41. Wang Y, Revelo MP, Sudilovsky D, Cao M, Chen WG, Goetz L, Xue H, Sadar M, Shappell SB, Cunha GR, Hayward SW. Development and characterization of efficient xenograft models for benign and malignant human prostate tissue. The Prostate. 2005; 64:149-159.

42. Philippeaux MM, Pache JC, Dahoun S, Barnet M, Robert JH, Mauel J, Spiliopoulos A. Establishment of permanent cell lines purified from human mesothelioma: morphological aspects, new marker expression and karyotypic analysis. Histochem Cell Biol. 2004; 122:249-260.

43. Vandesompele J, De Preter K, Pattyn F, Poppe B, Van Roy N, De Paepe A, Speleman F. Accurate normalization of realtime quantitative RT-PCR data by geometric averaging of multiple internal control genes. Genome biology. 2002; 3:Research0034.

44. Schaffner W, Weissmann C. A rapid, sensitive, and specific method for the determination of protein in dilute solution. Analytical biochemistry. 1973; 56:502-514.

45. Pass HI, Stevens EJ, Oie H, Tsokos MG, Abati AD, Fetsch PA, Mew DJ, Pogrebniak HW, Matthews WJ. Characteristics of nine newly derived mesothelioma cell lines. Ann Thorac Surg. 1995; 59:835-844. 